\title{
Males' and Females' EEG Responses and Image Maps for Emotional Evaluation Depending on Variation in Forms of Eyeliners
}

\author{
Min-Kyung Kim \\ Department of Beauty Care, Jangan University, Hwaseong-si, Gyeonggi-do, Korea
}

\author{
Corresponding author: Min-Kyung Kim, \\ Department of Beauty Care, Jangan \\ University, 1182 Samcheonbyeongma-ro, \\ Bongdam-eup, Hwaseong-si, Gyeonggi-do \\ 18331, Korea \\ Tel.: +82 312993316 \\ Tel.: +82 312993612 \\ Email: minkyung4567@jangan.ac.kr
}

Received May 24, 2019

Revised August 9, 2019

Accepted September 3, 2019

Published September 30, 2019

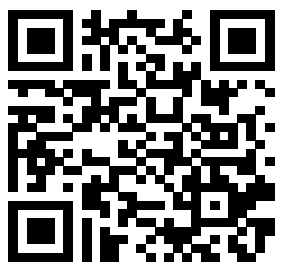

\begin{abstract}
Purpose: This study aimed to create image maps and understand the correlation between electroencephalography (EEG) and emotional responses by presenting a stimulus with modified forms of eyeliners to 30 males and 30 females aged in their 20s. Methods: The coefficient of variation for the brain wave (CVB) and favorability for and average preference index (API) of the eyeliners were examined. The correlation between brain waves and favorability was analyzed and an attempt to position the resulting API on an adjective image map was made. Statistical analysis of EEG and emotional evaluation was performed using SPSS, followed by repeated measure analysis of variance and post-test with Turkey's test at 95\% confidence level. Results: When the EEG responses of the male and female participants were stimulated by no-eyeliner (NL), the $\alpha$-wave was less reduced; when the EEG responses were stimulated by pin-up eyeliner (PU), $\beta$-wave, and $\gamma$-wave, SEF50 and SEF90 were most notably activated. Both instances showed similar EEG responses and APIs, depending on the variation in eyeliner forms. Although there was a low correlation between each form of eyeliners and favorability and API, there was a high correlation between API and SEF50 for both. On the adjective image map, the API of PU was evenly distributed in the range of positive and negative images for male and female participants, and they were entirely evaluated as strong and dynamic ones. Both the male and female participants demonstrated favorability for the basic eyeliner (BC) form of the eyeliners, followed by arabic eyeliner (AA) and NL. Conclusion: The results of the EEG and emotional responses, depending on the variation in eyeliner forms, suggest a basic direction of face image expressions. This technology could acquire scientific data for prospective image building of women, if correlations among physiological and emotional responses can be drawn, by applying eyeliners to various eye-shapes.
\end{abstract}

Keywords: Eyeliners, Males'and females', EEG, Emotional, Image maps

\section{Introduction}

현대 사회에서는 다양한 미디어를 접하게 됨에 따라 개인의 외형을 다양화와 차별화하려고 한다. 특히 메이크업을 수단으로 이미지를 개 선시키고, 변화되며 좋아 보이도록 한다. 메이크업은 얼굴에 색상을 부여하고 형태를 왜곡하여 얼굴의 장점을 부각시키고 단점을 보완하 여 이미지를 결정짓는 중요한 수단으로 생각하게 되었다(Cho, 2018; Kim \& Kang, 2003).
메이크업 컬러 트렌드 이미지 분석은 색상이 가지고 있는 고유한 특성이 얼굴 이미지를 좌우한다고 한다(Cho, 2018; Han, 2015; Ko $\&$ Lee, 2012). 뿐만 아니라 메이크업 컬러는 테라피에 적용 시 효과 적(Baek et al., 2013; Oh \& Lee, 2018)이며 메이크업 컬러가 인상 형성에 미치는 영향이 크다고 한다(Ko \& Ryu, 2009; Ryu, 2015; Yun \& Jung, 2016). 메이크업 관한 보고들은 대부분 컬러 적용에 의 한 변화된 이미지와 효과에 대한 연구들이었다. 이렇듯 컬러를 적용 한 메이크업에 관한 연구는 많았으나 메이크업의 형태변화에 관한 연 
구들은 미미하였다.

강수진과 유태순의 연구에 의하면 방송 제작시스템 변화에 따른 여성 앵커의 메이크업에 관하여 분석하였으나(Kang \& Yoo, 2016), 형태에 관한 것은 눈썹과 입술로만 국한되어 다양한 메이크업 테크 닉에 대한 결과를 도출하기엔 부족하였다. 그 외 메이크업의 테크닉 변화에 의한 지각파악은 대부분 눈과 눈썹의 형태에 의한 것이거나 (Cho et al., 2010; Park \& Kim, 2017; Park \& Park, 2019; Song $\&$ Park, 2004) 얼굴형태에 변화에 의한 이미지 연구들이었다(Kim, 2007; Kang, 2008). 형태에 대한 보고 중 스모키 메이크업의 변화에 의하여 다양한 이미지가 전달된다고 한다(Kim \& Ryu, 2011). 이 결 과는 여러 가지 형태의 스모키 메이크업이 다양한 감성 이미지를 유 도할 수 있음을 파악되었다. 그 외 아이라이너의 표현기법을 연구한 선행연구는 시대의 흐름에 따라 기법이 다양해졌으며 사회변화에 따 라 의식이 아이라이너 형태에 적용되었다고 한다(Kim, 2016; Park \& Lee, 2008). 그리고 아이라이너 형태변화에 의한 감성반응을 형용 사 이미지 맵에 포지셔닝 한 결과 얼굴 이미지 변화 시 아이라이너의 형태에 의하여 다양한 이미지로 연출할 수 있음이 파악되었다(Kim, 2014). 이렇게 메이크업을 이루는 요소(아이 쉐도우, 아이라이너, 립) 들에 대한 연구는 많았으나 이미지를 정량화 하기는 부족한 부분이 있었다. 본 연구는 아이라이너의 형태를 변화시킨 자극물을 제시하여 20 대 남녀를 대상으로 뇌파 측정하여 정량화하여 과학적 데이터를 획 득하기 위함이다. 더불어 남녀의 감성평가 이미지 맵 구축과 동시에 뇌파와 감성반응의 상관관계를 파악하고자 한다.

\section{Methods}

\section{1. 실험재료}

자극물은 패턴북에 있는 기본형 눈에 원래의 아이라이너를 그 리지 않은 눈과 5 가지 아이라이너의 형태로 변화를 주어 제작하였 다(Kim \& Hong, 2018). 아이라이너를 그리지 않은 no liner의 형태를 NL, basic 아이라인은 BC, slept-in smudge의 아이라인 은 SS, dropped flick의 아이라인은 DF, pin-up의 아이라인은 PU, Arabic 형태의 아이라인은 AA라 하였다(Table 1). 일러스트 된 눈의 틀에 색연필을 이용하여 변화를 주었으며(Kim \& Hong, 2018), 아이라이너에 의한 반응만 보기 위해 외부 자극인 피부색 과 입술을 배제시켜 눈과 눈썹 만을 일러스트레이션 하였고 이 자 극물들을 스캔하였다. 스캔 된 6 가지의 자극물들은 피험자들에게 모니터로 제시하였다.

\section{2. 실험 대상 및 뇌파 측정방법}

서울 경기도 소재의 20 대 남녀 대학생, 남자 30 명(평균 $25.2 \pm$ 0.8 세), 여자 30 명(평균 $23.2 \pm 0.7$ 세)을 대상으로 실험을 진행하 였다. 피험자들은 beck depression inventory (BDI)측정을 통하
여 신경학 또는 정신질환 병력이 없으며, 색맹이 아닌 정상적인 시각 기능을 가진 대상 만을 선발하였다. 본 연구는 헬싱키윤리기 준과 임상시험기준을 준수했으며, 보건복지부 지정 공용기관 인 생명윤리위원회의 승인을 받았다(승인번호: P01-201807-11002).

피험자에게 자극물은 모니터(24MP47HQ; (주 LG, KOREA) 를 통해 제시하였다. 뇌파측정(electroencephalogram, EEG) 은 QEEG 32 system (Laxtha, Korea)을 사용하였고, 뇌파 캡 (Electro-cap-medium 21ch, ECI. USA)을 이용하여 피험자 머리에 씨어 측정하였다. 뇌파 캡(electro-cap-medium $21 \mathrm{ch}$, ECI, USA)은 21부위(Fp1, Fpz, Fp2, F3, F4, F7, F8, Fz, T3, T4, C3, C4, Cz, P3, P4, Pz, T5, T6, O1, Oz, O2)에 국제 1020 전극 배치법의 기준에 의한 센서가 부착되어 있다. 측정 전 피 험자가 안정 상태를 유지할 수 있도록 눈을 감은 채 3-5 min 동 안 명상을 취한 후 편안한 상태에서 자극물이 있는 컴퓨터 모니터 를 $20 \mathrm{~s}$ 동안 응시하도록 하여 뇌파를 수집하였다. 무작위 순서 로 제시되는 자극물을 보고 있는 동안 눈 깜빡임은 데이터 처리과 정에서 제거하였다. 자극물 측정 후 바로 감성평가를 하였으며, 피로감을 주지 않기 위하여 측정 중간에 휴식을 취하였다(Kim, 2017; Kim, 2018).

\section{3. 감성평가}

각각의 아이라이너 형태 변화에 의한 감성평가는 형용사 척도 를 10 point $(-5$ to 5$)$ 로 설문 문항을 구성하였다. 감성형용사 는 Kim \& Ryu (2011), Kim (2017), Kim (2018)의 선행연구 와 image research institute (IRI)의 이미지 형용사 스케일에 서 사용한 단어를 추출하였다(Kim \& Ryu, 2011; Kim, 2017; $\mathrm{Kim}, 2018)$. 감성형용사는 깊은-얕은, 정적인-활동적인, 인 공적인-자연적인, 멋진-사랑스러운, 남성적인-여성적인, 딱

Tables 1. Forms of no liner and each Liner and aplication of 5 eyeliner forms to eyes with no liner

Munsell stimulus of value change
No eyeliner
Bropt-in smudge eyeliner
Arabic eyeliner



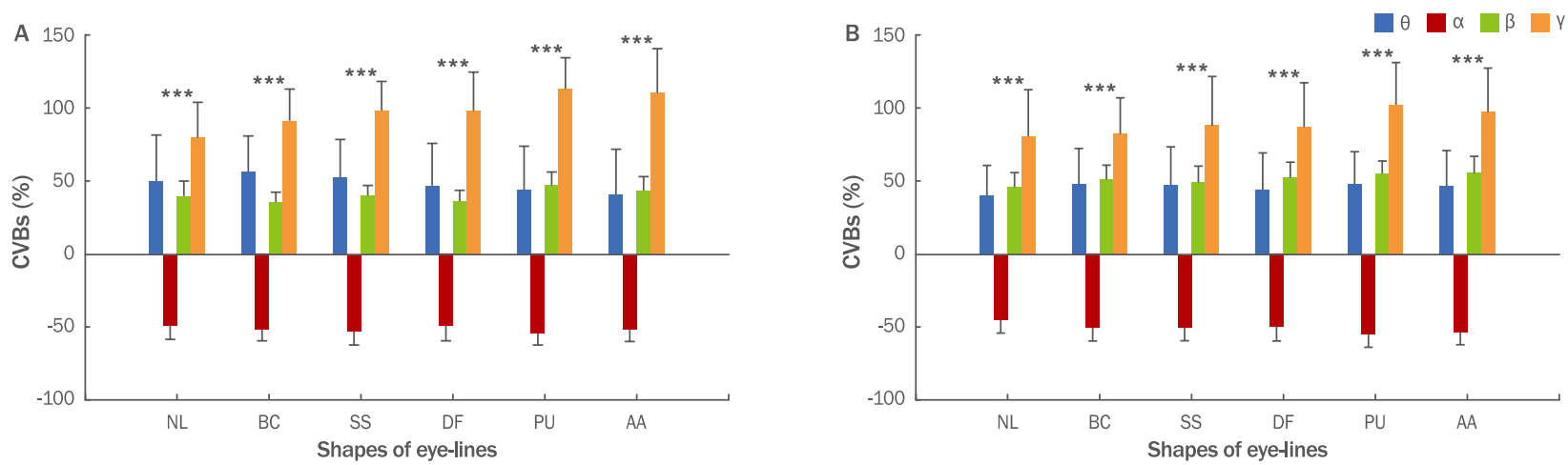

Figure 1. CVB of males and females, depending on variation in forms of eyeliners.

(A) male; (B) female. NL, no eyeliner; BC, basic eyeliner; SS, slept in smudge eyeliner; DF, dropped flick eyeliner; PU, pin-up eyeliner; AA, arabic eyeliner; CVB, coefficient of variation for the brainwave; $\theta$, relative theta power; $\alpha$, relative alpha power; $\beta$, relative beta power; $\gamma$, relative gamma power; ${ }^{* * *} p<0.000$.

딱한-부드러운, 어두운-밝은, 서양적인-동양적인, 나이든-젊 은, 강인한-연약한, 무거운-가벼운, 탁한-맑은, 복잡한-단순 한, 시원한-포근한 7쌍으로 구성하였다. 7쌍의 감성 형용사 선호 도 지수(preference index, PI) 개념을 도입하여 감성 평가를 분 석하였고, 감성 형용사의 평균 선호도 지수(average preference index, $\mathrm{API}$ 를 이용하여 명도와 채도 변화의 상관관계를 분석하 였다(Chang et al., 2017; Kim, 2017; Kim et al., 2018; Kim, 2018). 각 아이라이너의 형태 변화에 의한 API결과값은 이미지 형용사 맵의 위치에 각각 포지셔닝하여 남성과 여성의 감성반응을 비교하였다. 각 아이라이너 형태에 대한 호감도(favorability)는 5 점척도(1-5)로 평가하였다.

\section{4. 분석방법}

각 눈에 아이라이너의 형태를 변화시켜 수집한 뇌파값은 Telescan 프로그램을 이용하여 정량적 데이터를 획득하였다. 0-50 Hz의 주파수 영역 중에 눈 굴림이나 안면 근육의 움직임에 따라서 영향을 많이 받는 델타파 $(0-4 \mathrm{~Hz})$ 제거 후 fast fourier transform (FFT)의 알고리즘을 이용하여 나머지 주파수 대역(4$50 \mathrm{~Hz}$ )의 파워 스펙트럼을 분석하였다. 전체 주파수 대역의 상 대 파워값(relative power values, RPVs)인 가수면과 초능력 발 휘 시 활성되는 세타파(relative theta power, $\theta$ 파: 4-8 Hz), 이 완 시 증가되는 상대 알파파(relative alpha power, $\alpha$ 파: 8-13 $\mathrm{Hz}$ ) 각성의 경우 출현하는 상대 베타파(relative beta power, $\beta$ 파: 13-30 Hz) 집중 시 출현하는 상대 감마파(relative gamma power, $\mathrm{Y}$ 파: 30-50 Hz로 분석하였다. 자극이 없는 상태의 바 탕 뇌파(RPVs) 대비 아이라이너 형태변화에 의한 상대 뇌파 파 워 차이의 비율인 뇌파변동계수(coefficient of variation for the brainwave, CVB)로 분석하였다. 각 자극에 대한 모서리 주파수 의 변화는 바탕 뇌파 평균값 대비 각 자극에 대한 모서리 주파수
값의 편차로 평가하였다(Chang et al., 2017; Kim et al., 2018; Kim, 2018). 뇌파 반응에 따른 통계 분석은 Statistical Package for the Social Sciences (SPSS) ver.22.0 (IBM, USA)을 사용하 여 반복분산분석(repeated measure analysis of variance)을 실 시하였으며, $95 \%$ 신뢰수준에서 Tukey's test를 통해 사후검증을 하였다(Jung et al., 2015; Kim, 2018).

\section{Results}

\section{1. 아이라이너 형태 변화에 의한 남녀의 뇌파반응}

1) 뇌파변동계수

Eye-line 없는 형태의 눈은 NL, basic 아이라인은 BC, sleptin smudge의 라인은 SS, dropped flick의 라인은 DF, pin-up의 라인은 PU, arabic eyeliner형태는 $\mathrm{AA}$ 로 명시하였다. 각 자극물 을 제시하여 뇌파측정 한 남녀의 뇌파변동계수 결과는 다음과 같 다(Figure 1).

남성의 $\theta$ 파는 $\mathrm{AA}$ 의 자극시 $40.7 \pm 31.0 \%$ 로 가장 작게 활성되 었고 $\mathrm{BC}$ 자극시 $56.5 \pm 24.3 \%$ 로 가장 크게 출현하였다. $\mathrm{NL}$ 의 자 극시 $\alpha$ 파의 값이 $-48.8 \pm 9.6 \%$ 로 가장 작게 감소하였고, $\mathrm{PU}$ 의 자극시 $-54.2 \pm 7.9 \%$ 로 가장 많이 감소하였다. $\beta$ 파는 $\mathrm{BC}$ 자극시 $35.5 \pm 6.9 \%$ 로 비활성되었으며 PU자극시 $46.8 \pm 9.3 \%$ 로 가장 활 성되었다. $\bigvee$ 파는 $\mathrm{NL}$ 자극시 $79.2 \pm 24.25 \%$ 로 가장 낮았으며 PU 자극시 $113.0 \pm 21.3 \%$ 로 가장 크게 반응하였다(Figure 1A). 여 성의 $\theta$ 파는 NL자극시 $40.0 \pm 20.7 \%$ 로 비활성되었으며 PU 자극 시 $48.0 \pm 22.1 \%$ 로 가장 활성되었다. $\alpha$ 파는 $\mathrm{NL}$ 자극시 $-44.7 \pm$ $9.2 \%$ 로 가장 적게 감소되었고, $\mathrm{PU}$ 자극에서 가장 $-54.4 \pm 9.2 \%$ 로 가장 많이 감소하였다. $\beta$ 파는 $\mathrm{NL}$ 의 자극 시 $45.8 \pm 10.0 \%$ 로 낮았고 $\mathrm{PU}, \mathrm{AA}$ 자극시 $55.2 \%$ 로 가장 높았다. $\mathrm{Y}$ 파는 $\mathrm{NL}$ 자극에서 

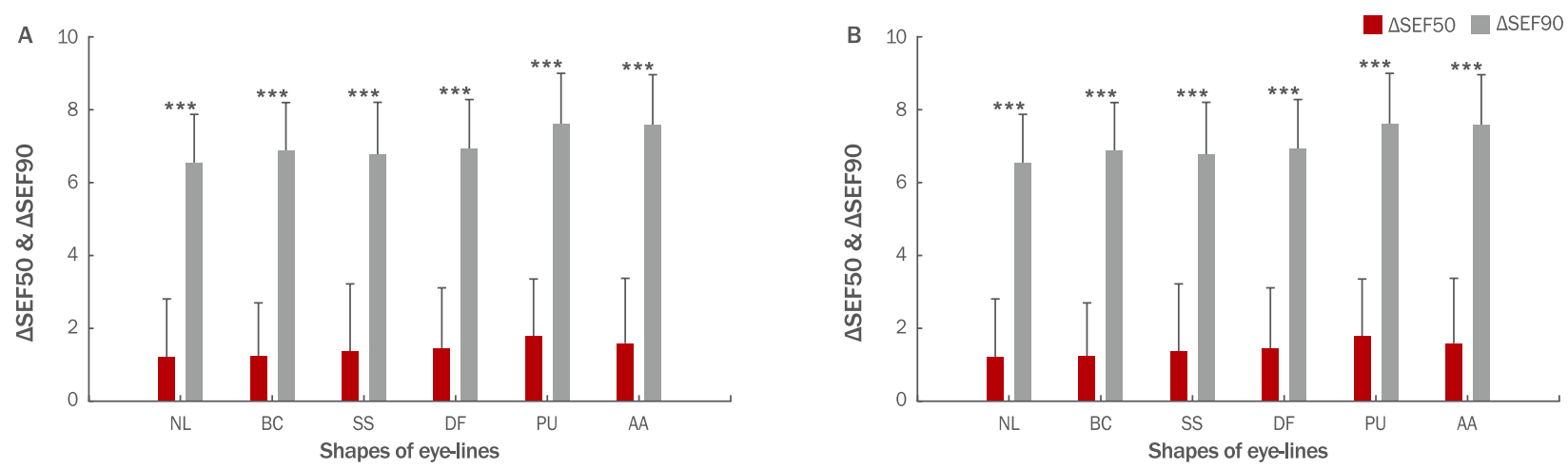

Figure 2. Males' and females SEF depending on variation in forms of eyeliners.

(A) male; (B) female. NL, no eyeliner; BC, basic eyeliner; SS, slept in smudge eyeliner; DF, dropped flick eyeliner; PU, pin-up eyeliner; AA, arabic eyeliner; SEF, spectral edge frequency; ${ }^{* * *} p<0.000$.

$80.6 \pm 31.8 \%$ 로 비활성되었고 PU자극에서 $102.1 \pm 28.9 \%$ 으로 가장 높았다(Figure 1B).

여성이 남성보다 $\beta$ 파의 활성도가 많이 높았으나 $\theta$ 파, $\mathrm{\gamma}$ 파는 남 성이 여성보다 조금 더 높게 활성되었다. $\alpha$ 파는 남녀 모두 $\mathrm{NL}$ 의 자극 시 덜 감소하였다. $\beta$, $\gamma$ 파의 반응은 PU자극시 남성과 여성 모두 비슷하게 가장 활성하였다. 바의 반응은 남녀의 반응이 상 이하게 도출되었다(Figure 1). 아이라이너의 형태변화에 의한 뇌 파반응은 남녀의 반응추이는 비슷하였다. 아이라인의 변화에 의 한 남성과 여성의 뇌파변동지수 $(\theta, \alpha, \beta, \gamma$ 파) 결과는 통계적으로 유의하였다(남: $p<0.000$, 여: $p<0.000$ ).

\section{2) 모서리주파수}

각 아이라이너 자극에 대한 모서리 주파수 $\triangle \mathrm{SEF} 50$ 과 $\triangle$ $\mathrm{SEF} 90$ ) 결과는 다음과 같다(Figure 2).

남성은 $\mathrm{BC}$ 자극에서 $1.6 \pm 1.5 \mathrm{~Hz}$ 였고 $\mathrm{PU}$ 의 자극에서 $2.6 \pm 1.9$ $\mathrm{Hz}$ 으로 증가 폭이 매우 컸다. $\triangle \mathrm{SEF} 90$ 의 반응은 $\mathrm{NL}$ 의 자극에서

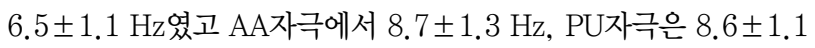
$\mathrm{Hz}$ 였다(Figure $2 \mathrm{~A}$ ). 여성은 $\mathrm{NL}$ 의 자극일 때 $\triangle \mathrm{SEF} 50$ 은 $1.2 \pm$ $1.6 \mathrm{~Hz}$ 였고, PU의 자극에서 $1.8 \pm 1.6 \mathrm{~Hz}$ 으로 증가 폭이 매우 컸
다. $\triangle \mathrm{SEF} 90$ 의 반응은 $\mathrm{NL}$ 일 때 $6.6 \pm 1.3 \mathrm{~Hz}$ 였으며, PU의 자극 에서 $7.6 \pm 1.4 \mathrm{~Hz}$ 였다(Figure $2 \mathrm{~B}$ ).

남성과 여성의 $\triangle \mathrm{SEF} 50$ 과 $\triangle \mathrm{SEF} 90$ 의 반응은 $\mathrm{PU}, \mathrm{AA}$ 의 자 극에서 가장 활성 되었다. 아이라이너 형태변화에 의한 뇌파 지 표( $\triangle \mathrm{SEF} 50, \triangle \mathrm{SEF} 90)$ 결과는 통계적으로 유의하였다(남: $p<0.000$, 여: $p<0.000)$.

2. 아이라이너 변화에 의한 뇌파반응과 호감도(favorability)의 상관 관계

남성은 $\mathrm{BC}$ 의 형태에서 3.8 로 가장 호감도가 높게 평가하였 다. 두번째로 높은 호감도는 라인이 없는 형태NL(3.3)였으며, SS (3.1) $\geq \mathrm{AA}$ (3.1)〉 $\mathrm{PU}(2.7)\rangle \mathrm{DF}$ (2.3)순이었다. 여성의 호감도 평 가도 $\mathrm{BC}$ 의 형태에서 3.7 로 가장 높게 평가되었다. $\mathrm{AA}$ 형태(3.4) 는 두번째로 높은 호감도로 평가되었다. NL (2.9)〉 SS (2.5)〉 PU (2.4) $>\mathrm{DF}$ (1.7)순으로 평가하였다(Table 2), 여성, 남성 모두 $\mathrm{BC}$ 의 형태를 가장 선호하였으며 $\mathrm{DF}$ 의 형태를 비선호 하였다. 남성 은 아이라인의 형태변화에 의한 호감도 평가의 범위(2.3-3.8)가 적었으나, 여성은 형태 변화에 의한 평가범위(1.7-3.7)가 크게 평 가하여 남성보다 여성의 호감도 평가 편차가 컸다(Table 2).

Table 2. Favorability of males and females depending on form of eyeliners

\begin{tabular}{lccccccc}
\hline & NL & BC & SS & DF & PU & AA \\
Man & $3.3 \pm 1.9$ & $3.8 \pm 1.1$ & $3.1 \pm 1.2$ & $2.3 \pm 1.4$ & $2.7 \pm 1.3$ & $3.1 \pm 1.5$ \\
Woman & $2.9 \pm 1.4$ & $3.7 \pm 1.2$ & $2.5 \pm 1.2$ & $1.7 \pm 1.3$ & $2.4 \pm 1.1$ & $3.4 \pm 1.2$ \\
\hline
\end{tabular}

$\mathrm{NL}$, no eyeliner; BC, basic eyeliner; SS, slept in smudge eyeliner; DF, dropped flick eyeliner; PU, pin-up eyeliner; AA, arabic eyeliner.

Table 3. API of males and females depending on form of eyeliners

\begin{tabular}{lccccccc}
\hline & NL & BC & SS & DF & PU & AA \\
Man & $1.8 \pm 0.1$ & $1.5 \pm 0.1$ & $1.6 \pm 0.1$ & $1.0 \pm 0.4$ & $0.5 \pm 0.3$ & $1.9 \pm 0.1$ \\
Woman & $1.3 \pm 0.2$ & $0.8 \pm 0.2$ & $2.5 \pm 0.2$ & $0.9 \pm 0.1$ & $-0.3 \pm 0.1$ & $1.3 \pm 0.2$ \\
\hline
\end{tabular}

$\mathrm{NL}$, no eyeliner; BC, basic eyeliner; SS, slept in smudge eyeliner; DF, dropped flick eyeliner; PU, pin-up eyeliner; AA, arabic eyeliner. 

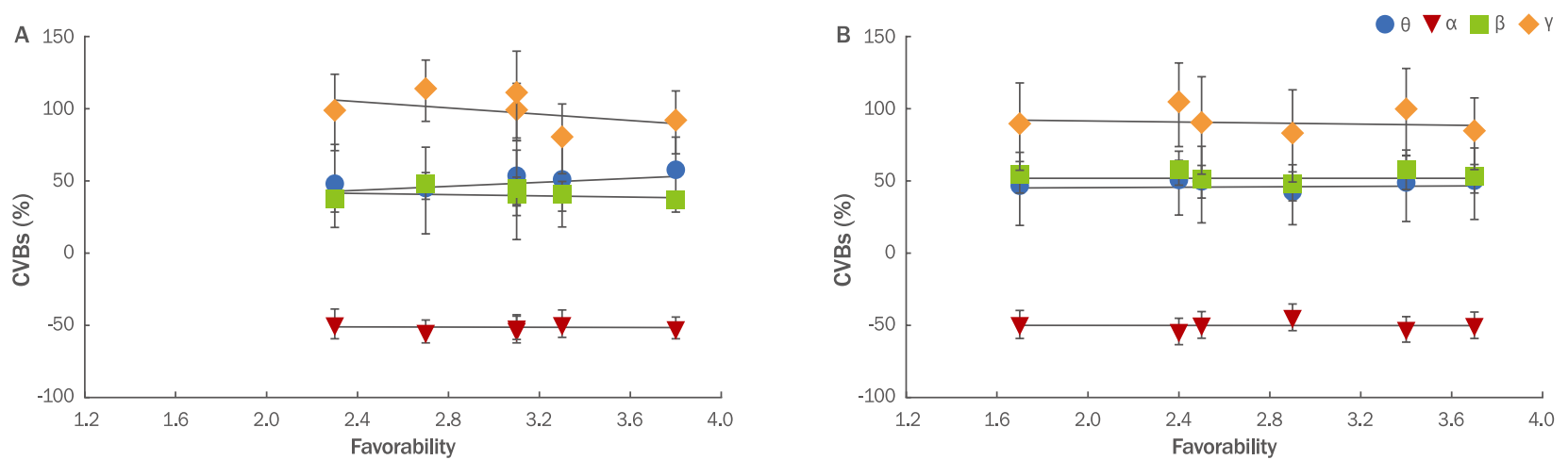

Figure 3. Correlation between favorability for forms of 5 eyeliners.

By 20s adults' testing the five eyeliner forms, we demonstrated the correlation relationship between CVBs and the favorability scale(1-5). The correlation between favorability and 5 eyeliner forms the correlation with a CVBs. Relation between evaluation of favorability for eyeliners and CVBs. CVBs and favorability according to variation in form of eyeliners applied to eyes. (A) male; (B) female.
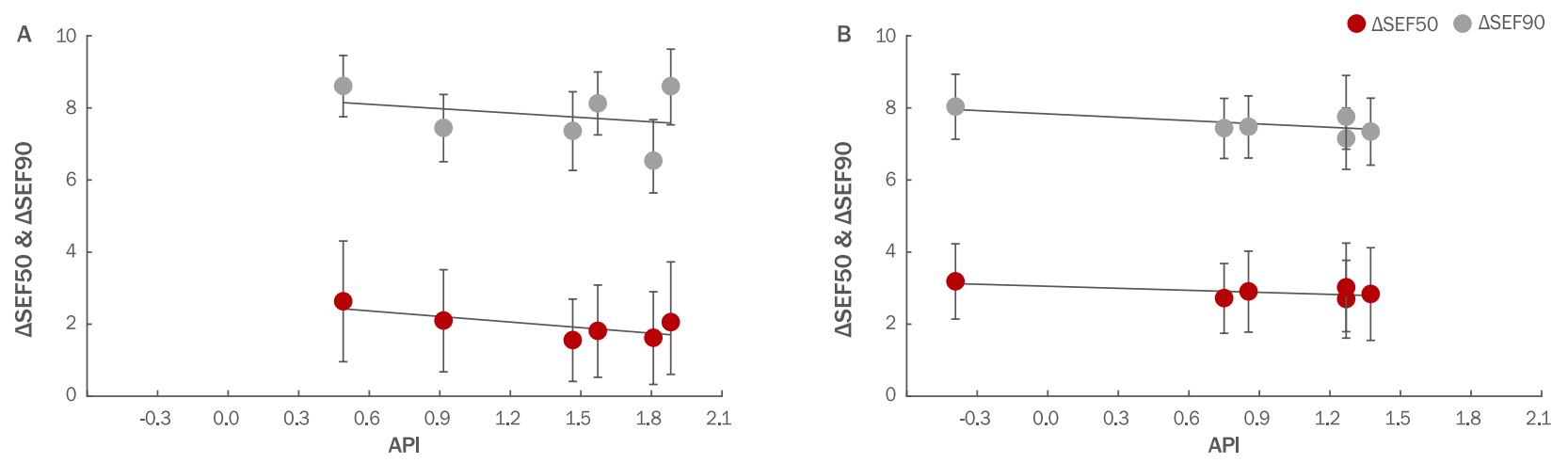

Figure 4. Correlation between EEG and API of 5 eyeliner forms.

The correlation between EEG and 5eyeliner forms the correlation with a SEF. SEF and favorability according to variation in form of eyeliners applied to eyes. (A) male; (B) female. SEF, spectral edge frequency.

남성의 아이라이너 형태에 대한 호감도와 측정된 뇌파변동계수 ( $\theta$ 파, $r^{2}=0.37 ; \alpha$ 파, $r^{2}=0.8 ; \beta$ 파, $r^{2}=0.06 ; \gamma$ 파, $r^{2}=0.21$ )의 상 관관계는 대체적으로 낮았다(Figure $3 \mathrm{~A}$ ). 여성도 역시 아이라이 너의 형태별 호감도와 뇌파변동계수의 상관관계 $\left(\theta\right.$ 파, $\mathrm{r}^{2}=0.03 ; \alpha$ 파, $r^{2}=0.02 ; \beta$ 파, $r^{2}=0.03 ; \gamma$ 파, $r^{2}=0.03$ )도 낮았다(Figure $3 B$ ).

\section{3. 아이라이너 형태변화에 따른 PI}

1) 남녀의 아이라이너 변화자극에 의한 모서리 주파수와 API 상관 관계

남성의 아이라이너 형태변화에 의한 API반응은 AA가 1.9 로 가 장 높았으며 $\mathrm{AA}>\mathrm{NL}>\mathrm{SS}>\mathrm{BC}>\mathrm{DF}>\mathrm{PU}$ 순이었다(Table 3). 아이라 이너 형태의API와 $\mathrm{SEF} 50$ 의 상관관계는 $\mathrm{r}^{2}=0.48, \mathrm{SEF} 90$ 의 상관 관계는 $r^{2}=0.07$ 이었다(Figure $4 \mathrm{~A}$ ).

여성의 API는 SS가 1.4 로 가장 높았으며 $\mathrm{NL}(1.3)$, $\mathrm{AA}>\mathrm{DF}>\mathrm{BC}>\mathrm{PU}$ 이었다(Table 3). 아이라이너 형태의API와
$\mathrm{SEF} 50$ 의 상관관계는 $\mathrm{r}^{2}=0.43, \mathrm{SEF} 90$ 의 상관관계는 $\mathrm{r}^{2}=0.32$ 이었다(Figure 4B). 여성이 남성보다 모서리주파수(SEF50, $\mathrm{SEF} 90)$ 와 $\mathrm{API}$ 의 상관관계가 높았다.

2) 아이라이너 변화자극에 의한 남성과 여성의 PI 이미지 맵

남성의 $\mathrm{NL}$ 의 $\mathrm{API}$ 는 전반적으로 부드러운 이미지로 평가하였 다. 특히 내츄럴(3.2), 맑은(2.7), 여성적인(2.4)이미지라고 높게 평가하였으며, 정적인(-1.6)이미지라고도 하였다(Figure $5 \mathrm{~A}$ ). $\mathrm{BC}$ 의 $\mathrm{API}$ 도 역시 양의 감성평가로 이루어졌다. 특히 여성적 (3.5), 젊은(2.8)이미지로 높게 평가되었으며 동시에 음의 감성인 깊은(-1.8) 이미지로 평가되었다(Figure 5B). SS의 API는 전반 적으로 부드러우며 정적인 이미지라고 평가하였다. 여성적(2.8), 맑은(2.3), 부드러운(2.3) 이미지라고 하였으며 정적인(-0.1) 이 미지도 내포하였다(Figure $5 \mathrm{C}$ ).

$\mathrm{DF}$ 의 $\mathrm{API}$ 는 여성적(2.5)이미지가 가장 높게 평가되었으며 인 
A

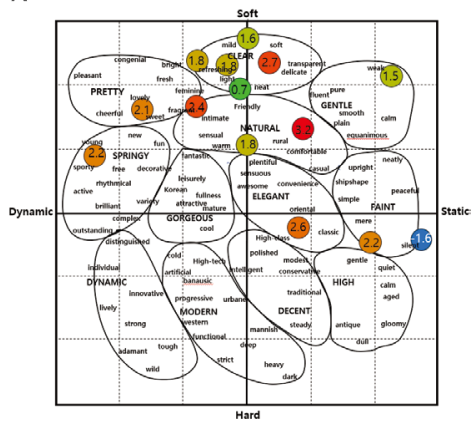

D

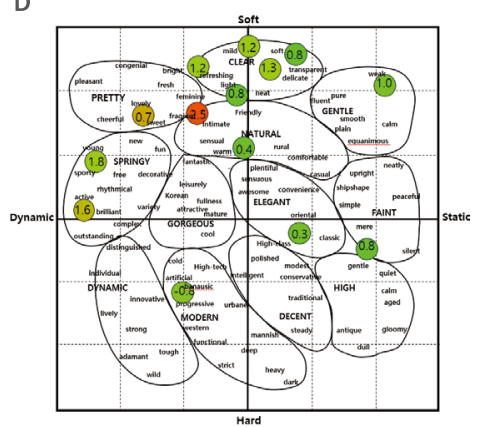

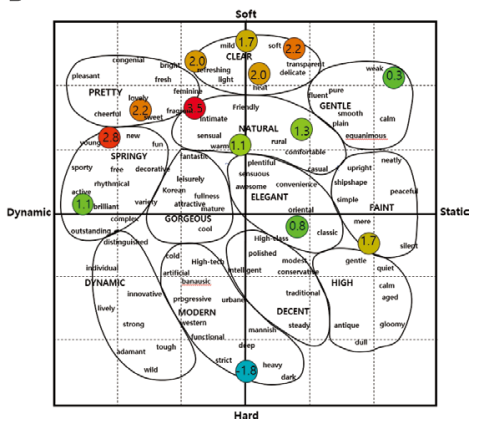

E

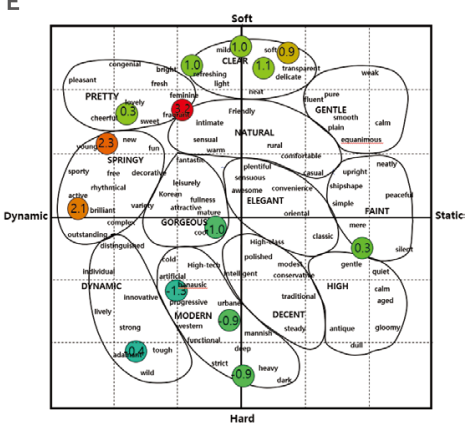

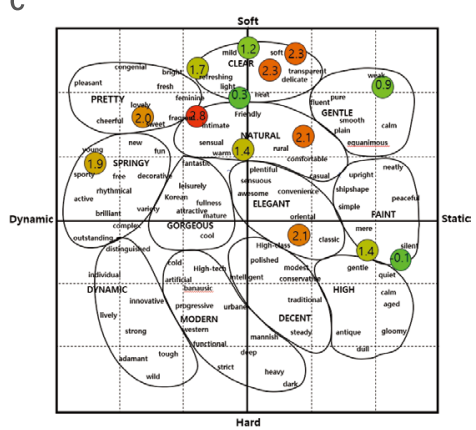

F

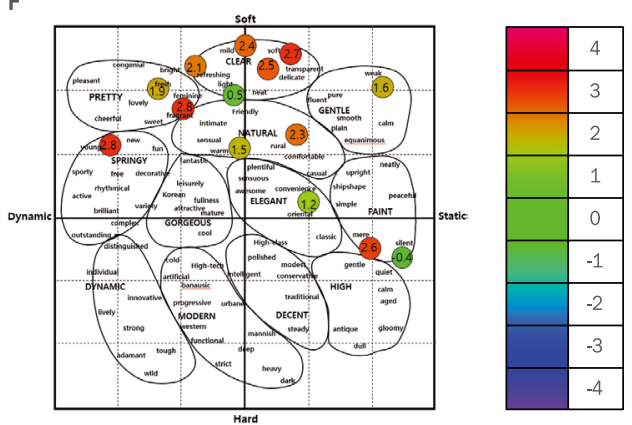

Figure 5. API by forms of eyeliners used by males, establishment of scientific data by positioning an API response of each eyeliner on adjective image maps.

(A) API of NL, (B) API of BC, (C) API of SS (D) API of DF (E) API of PU (F) API of AA . NL, no eyeliner; BC, basic eyeliner, SS, slept in smudge eyeliner; DF, dropped flick eyeliner; PU, pin-up eyeliner; AA, arabic eyeliner.

공적(-0.8)이다고 하였다(Figure 5D). PU의 API는 양과 음의 이 미지를 골고루 내포하고 있으며 그중 양의 이미지로 여성적(3.2) 이미지가 가장 높았으며, 젊고(2.3) 활동적(2.1)이라고 하였다. 반 면 음의 이미지로 인공적(-1.3), 서양적, 깊은(-0.9)라고 하였다 (Figure $5 \mathrm{E}$ ). $\mathrm{AA}$ 의 $\mathrm{API}$ 는여성적(2.8), 젊은(2.8)으로 평가되었으 며 음의 감성으로 정적인(-0.4) 이미지가 있었다(Figure $5 \mathrm{~F}$ ).

여성의 각 아이라이너의 $\mathrm{API}$ 는 NL의 자극 시 자연스러운(3.5)이 미지가 가장 높게 평가되었으며 동양적(2.3)이미지라고 하였고, 음 의 이미지인 정적인(-1.6) 이미지도 공존하였다(Figure $6 \mathrm{~A}) . \mathrm{BC}$ 의 $\mathrm{API}$ 는 여성적(2.9), 맑은(2.5)이미지인 양의 이미지와 깊은(-2.3) 과 같이 음의 감성도 존재하였다(Figure $6 \mathrm{~B}$ ).

$\mathrm{SS}$ 의 $\mathrm{API}$ 는 자연스러운(2.4)이라고 하였으며 음의 감성인 깊은 $(-0.5)$, 정적인(-0.4) 이미지로도 평가하였고(Figure $6 \mathrm{C}) \mathrm{DF}$ 의 $\mathrm{API}$ 는 자연스러운(2.4), 여성적(2.1), 그리고 동시에 깊은(-0.5), 정적인(-0.4) 이미지로 음의 감성이 있었다(Figure 6D).

$\mathrm{PU}$ 의 $\mathrm{API}$ 는 활동적(2.6), 여성적(2.5) 이미지 그리고 음의 이 미지인 강인한, 성숙한(-2.2), 인공적인(-2.1)으로 평가하였다 (Figure 6E). AA의 API는 자연스러운(3.0), 맑은(2.4), 부드러운 (2.3)이미지가 주를 이루었으며 음의 이미지인 깊은(-1.2) 감성도
있었다(Figure 6F).

$\mathrm{NL}$ 의 API는 남녀 모두 자연적인 이미지가 높게 평가되었으며 음의 이미지인 정적인 느낌도 공존하였다. $\mathrm{BC}$ 의 $\mathrm{API}$ 는 남녀 모 두 여성적이고 젊은 이미지로 느껴진다고 했다. 여성은 남성에 비 하여 형용사 이미지가 음양으로 골고루 넓게 분포된 반면, 남성은 양의 이미지로 치우쳐 있었다. SS의 $\mathrm{API}$ 는 남녀 모두 여성적이며 자연스러운 이미지라고 평가하였다. $\mathrm{DF}$ 의 $\mathrm{API}$ 는 남녀 모두 여성 적인 이미지가 강하다고 하였다. $\mathrm{PU}$ 의 $\mathrm{API}$ 는 남녀 모두 다른 아 이라이너의 형태보다 양과 음의 이미지가 골고루 분포하였다. $\mathrm{AA}$ 의 API는 남녀 모두 주로 양의 이미지인 맑고 부드러우며 젊은 이 미지가 높게 평가되었다. 각 아이라이너의 형태변화에 의한 API 는 남녀 모두 비슷한 반응으로 평가되었다(Figure 5, Figure 6).

\section{Discussion}

각 아이라이너형태의 뇌파반응 결과는 남녀가 동일하게 NL의 형태에서 $\alpha$ 파가 덜 감소하였으며, PU의 형태에서 $\beta$ 파, $\gamma$ 파가 가 장 활성 되었다. SEF50과 SEF90의 반응 역시 남녀모두 PU형태 
A

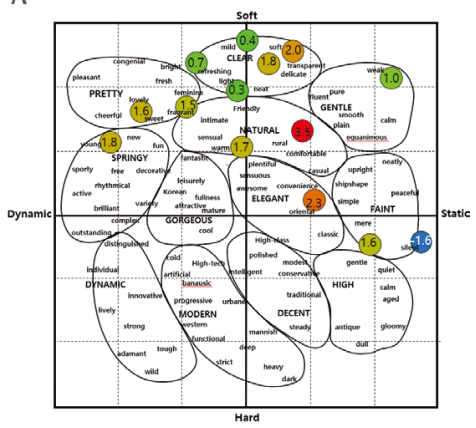

D

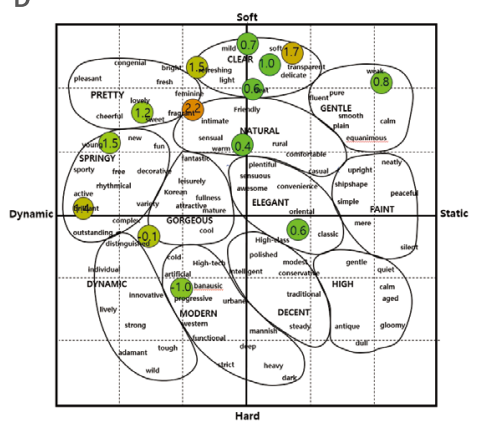

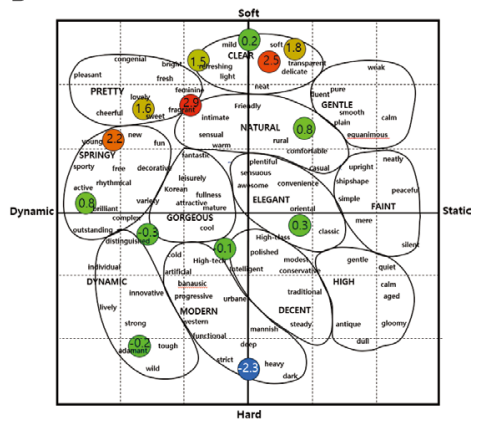

E

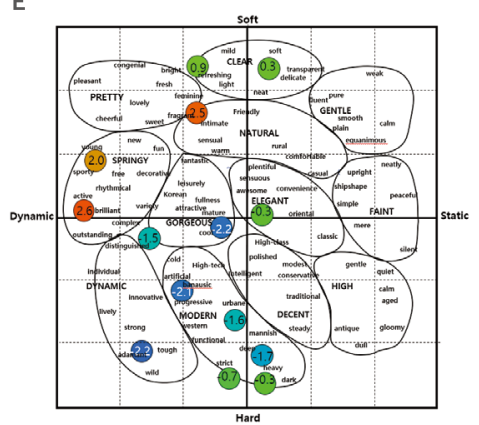

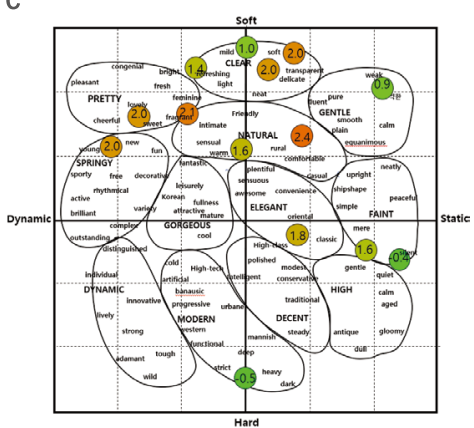

F

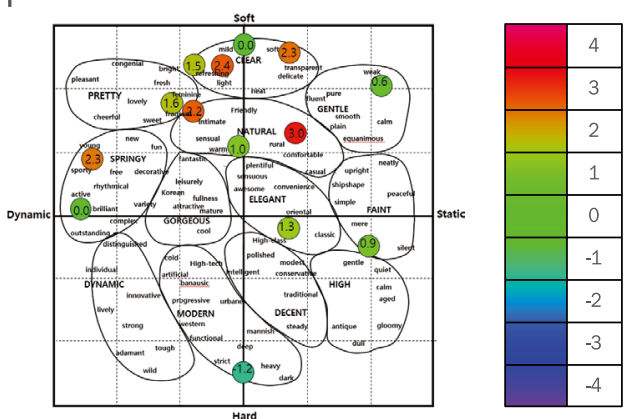

Figure 6. API by forms of eyeliners used by females, establishment of scientific data by positioning an API response of each eyeliner on adjective image maps.

(A) API of NL, (B) API of BC, (C) API of SS (D) API of DF (E) API of PU (F) API of AA . NL, no eyeliner; BC, basic eyeliner, SS, slept in smudge eyeliner; DF, dropped flick eyeliner; PU, pin-up eyeliner; AA, arabic eyeliner.

에서 가장 활성되었다(Figure 1, Figure 2). 남녀 모두 각각의 아 이라이너 형태에 의한 호감도와 뇌파변동계수와의 상관관계는 낮 았다(Figure 3). 남녀 모두 동일하게API와 $\triangle \mathrm{SEF} 50$ 의 상관관계 가 있었고(Figure 4) 각 아이라이너의 API를 형용사 이미지 맵에 포지셔닝 한 결과 남녀 평가가 비슷하게 포지셔닝 되었다(Figure 5, Figure 6).

바탕색과 무늬의 대비가 큰 색상 자극시 각성시 활성되는 감마 파의 증가현상이 유의미하게 작용하였으며, 휴식과 안정의 의미 인slow alpha가 활성되었다(Lee et al., 2017). 이 결과는 본 연 구에서 시각적으로 자극되고 서양적 이미지와 강한 형태인 PU 자 극에서 베타와 감마파의 활성 정도가 높게 출현한 결과와 비슷하 였다.

본 연구에서 뇌파측정 시 남녀 모두 PU와 $\mathrm{AA}$ 의 자극에서 각성 시 활성되는 베타파와 집중시 활성되는 감마파도 컸으며, 집중과 각성 지수인 SEF50과 SEF90의 증가폭도 높았다. AA자극의 남 녀 호감도 평가가 3.1-3.4로 높았다(Table 2). 눈꼬리가 올라간 스타일인 PU는 남녀 모두 화려하고 인공적, 강인한 이미지로 API 를 평가하였다(Figure 5, Figure 6). PU의 API평가는 전체적으 로 강한 각성과 긴장된 감성으로 평가되었고 뇌파반응은 각성과 스트레스 지표인 $\beta$ 와 $ү$ 파의 활성도(Figure 1)가 가장 높아 감성평
가(API)와 뇌파와 상관관계가 있음을 유추할 수 있었다. 대조배색 에서 베타파와 감마파가 활성 된 결과(Kim, 2018)는 강한 이미지 $\mathrm{PU}$ 의 자극에서 베타파와 감마파 상승된 결과를 지지한다.

No makeup, light makeup과 heavy makeup의 자극의 ERPs 측정결과는 heavy makeup에서 N170의 진폭이 크게 나타났다 (Tagai et al., 2017). N170의 진폭은 얼굴의 차별성이 클 때 크 게 나타난다고 한다(Schulz et al., 2012). 이 결과들은 heavy makeup이 얼굴에 자극이 큰 것으로 파악된다. Light makeup은 heavy makeup과 no makeup의 얼굴보다 선호함을 시사하였다. 본 연구에서 $\mathrm{ERP}$ 측정은 아니었으나 메이크업 형태에 따라 뇌파 (EEG)변화가 있음을 시사한다.

한국, 중화권, 일본에서 선호하는 아이라이너 형태는 눈꼬리가 올라간 스타일이라고 한다(Kim \& Li, 2014). 그리고 아이라이너 의 형태가 상승형인 경우 다이나믹하고 인공적, 도시적이라는 보 고이다(Kim, 2014). 본 연구에서도 역시 $\mathrm{AA}$ 의 자극에서 3.13.4 의 호감도로 높게 평가하였으며, $\mathrm{PU}$ 와 $\mathrm{AA}$ 의 $\mathrm{API}$ 가 동적이며 다이나믹 한 감성과 일치하였다. 본 연구에서는 아이라이너 형태 에 의한 뇌파와 호감도와의 상관관계는 낮았으나(Figure 3) 컬러 변화에 의한 뇌파반응과 호감도와의 상관관계는 높게 평가되었다 (Aprilianty et al., 2016; Kim, 2018). 아이 쉐도우 컬러변화에 
의한 뇌파반응의 상관관계는 높았으나 형태변화에 의한 호감도와 상관관계는 컬러변화에 의해서 보다는 낮은 것으로 유추할 수 있 었다.

박희진과 이정민의 연구에 의하면 아이라이너의 제형에 따라 표현기법이 다양하며, 시대적 상황에 맞도록 여러 형태로 연출되 었다고 한다(Park \& Lee, 2008). 더불어 젊은이들의 현실에 대한 사회적 의식이 아이라이너 표현 기법에 나타났다고 한다. 이처럼 아이라이너는 다양한 이미지 표현을 추구하고 싶은 여성의 심리가 잘 표현되어 여러 아이라이너 종류들은 원하는 이미지 연출을 위 하여 다양하게 활용할 수 있을 것으로 사료된다. 짧은 아이라이너 형태는 귀엽고 사랑스러운 이미지, 긴 형태는 온화, 순수, 자연적 인 이미지, 보통의 길이의 아이라이너 형태는 자연스럽고 친근하 며 감성적 이미지, 눈 꼬리가 처진 모양은 점잖고 보수적, 눈 꼬리 가 올라간 형은 다이나믹, 도시적, 인공적 느낌으로 연상되었다고 하였다(Kim, 2014). 앞선 보고와 본 연구결과는 아이라이너 형태 에 의하여 다양한 이미지 연출이 가능한 것으로 추정된다.

외모에 관심이 많은 여중생이 색조화장품( $\mathrm{BB}$ 크림, 립, 아이라 인, 마스카라)를 사용하여 자신의 얼굴을 연출한다고 하였다( $\mathrm{Na}$ \& Song, 2014). 외모를 꾸미기 위하여 여중생들도 사용한다는 결 과는 이러한 색조화장품을 이용하여 용모변화를 추구할 수 있었 다. 본 연구에서도 여러 아이라이너의 형태에서 타인에게 전달되 는 이미지가 다른 것으로 파악된다. 20대 여대생의 경우 최신 트 랜드와 선호하는 경향이 비슷하였으며 30-40대의 직장에 다니 는 여성은 트랜드와 무관하게 일반적인 평범한 형태를 선호였다 (Kim, 2014). 본 연구에서 남녀가 호감도(3.7-8.8)를 보이는 아 이라이너 형태는 $\mathrm{BC}$ 인 일반적인 아이라이너 형태였다. 선행된 보 고에서 30-40대 여성들이 선호하는 스타일과 동일하였다. 이 결 과는 연령이 달라도 기본형 스타일을 남녀가 호감하는 스타일임을 유추할 수 있었다.

\section{Conclusion}

20 대 남녀 60 명을 대상으로 아이라이너의 형태변화에 의한 뇌 파와 감성반응은 다음과 같았다.

남녀 모두 아이라이너 형태에 의한 뇌파반응은 $\mathrm{NL}$ 의 형태에 서 $\alpha$ 파가 덜 감소하였으며, PU의 형태에서 $\beta$ 파, $\gamma$ 파, SEF50, $\mathrm{SEF} 90$ 이 가장 증폭되었다. 여성이 남성보다 $\beta$ 의 활성도가 많이 높았으나 각 주파수의 증감의 경향차이는 없었다. 남녀 모두 아이 라이너 호감도는 $\mathrm{BC}$ 가 가장 높았으며 $\mathrm{AA}$ 와 $\mathrm{NL}$ 에서도 호감도가 3 이상으로 높게 도출되었다. 아이라이너 형태에 의한 뇌파와 감성 평가는 남녀 간의 차이가 없었다. 여러 형태의 아이라이너 호감도 평가와 뇌파변동계수와의 상관관계는 낮았으나, 남녀 모두 API와 $\mathrm{SEF} 50$ 의 상관관계는 있었다. 각 아이라이너들의 API를 형용사
이미지 맵에 포지셔닝 한 결과 남녀의 평가가 거의 비슷하였다. 특히 PU의 자극에서 $\mathrm{API}$ 반응이 양과 음의 이미지가 고르게 분포 되었고, 전반적으로 강하고 동적이며 딱딱한 이미지로 평가되었 다. 따라서 본 연구 결과들은 과학적 근거하에 아이라이너가 얼굴 이미지표현을 위한 수단으로 방향성을 제시할 수 있을 것으로 사 료된다. 향후 다양한 눈모양에 아이라이너를 적용하여 생리적·감 성적 반응의 상관관계를 도출하면 여성 이미지구축을 위한 과학적 데이터 베이스 구축이 이루어 질 것이다.

\section{Acknowledgements}

본 연구는 2019년도 장안대학교 연구비 지원으로 수행된 것으 로 이에 감사드립니다.

\section{References}

Aprilianty F, Purwanegara MS, Suprijanto. Effects of colour towards underwear choice based on electroencephalography (EEG). Australasian Marketing Journal (AMJ), 24: 331-336, 2016.

Baek SY, Lee SB, Ahn JR, Lee JM. The make up of being applied color therapy. Journal of Beauty Art Managemnet, 7: 283-292, 2013.

Chang YJ, Kim MK, Ryu HW. Effects of inhalation of oxides (caryophyllene oxide, eucalyptol, and linalool oxide), the major ingredient of essential oils, on human emotions and EEG responses. Journal of Odor and Indoor Environment, 16: 410-422, 2017.

Cho EM, Kim SH, Lee YJ, Yang JS, Kim KY. Correctional effects of unsymmetric eyes by makeup. Journal of the Korean Society of Beauty and Art, 11: 1-12, 2010.

Cho MJ. Analysis of image makeup using color trends. Asian Journal of Beauty and Cosmetology, 16: 499-507, 2018.

Han HJ. Effects of makeup on facial images of illustrations. Journal of Korea Society of Color Studies, 29: 49-58, 2015.

Jung SM, Kim MK, Ryu HW. Influence of the concentration of jasmine oil on brain activity and emotions. Journal of Odor and Indoor Environment, 14: 270-278, 2015.

Kang GY. A Study of image through morphological analysis on the physiognomy. The Journal of the Korean Society of Make-up Design, 4: 279-288, 2008.

Kang SJ, Yoo TS. Analysis and demostration of female 
anchors makeup according to the changes in the broadcasting production system. Journal of Korea Design Forum, 53: 17-28, 2016.

Kim EY, Kim MK, Kim ST, Ryu HW. Comparison of relaxation and calming effect of foot bath and lavender foot bath by EEG and emotional responses analysis. Journal of Odor and Indoor Environment, 17: 122-131, 2018.

Kim HS, Kang IA. A study on the image make-up according to theme. Journal of Fashion Business, 7: 72-83, 2003.

$\mathrm{Kim} \mathrm{JH}$. The study of standard face shape analysis of adult women for make-up. Journal of the Korean Society of Costume, 57: 151-165, 2007.

Kim MK. The study of emotional reaction affecting the face image according to illustration various form of eyeliner. Asian Journal of Beauty and Cosmetology, 12: 217-223, 2014.

Kim MK. Correlation between the factors of personal color diagnosis guide and brain wave analysis. Asian Journal of Beauty Cosmetology, 14: 407-416, 2016.

Kim MK. Brain recognition and sensibility response according to the shape of eyes and eyeshadow tone. Asian Journal of Beauty Cosmetology, 15: 421-434, 2017.

Kim MK. Brain waves and emotional responses, according to color stimulation of eye shadows using contrast and similar color arrangement. Asian Journal of Beauty and Cosmetology, 16: 509-521, 2018.

Kim MK, Hong SK. Make up pattern design book. Jigu, Paju, pp52-54, 2018.

Kim MK, Ryu HW. Analysis of emotional images according to eyes shapes and smoky makeup tone. Science of Emotion \& Sensibility, 14: 321-330, 2011.

Kim SY, Li S. A study on point make up preference and image of Korean, greater Chinese, Japanese and Thai women. Asian Journal of Beauty and Cosmetology, 12: 709-717, 2014.

Ko HS, Ryu JW. The effect of female's lip color and subject's traits on the impression formation. The Journal of the Korean Society of Make-up Design, 5: 203-214, 2009.

Ko JH, Lee JY. A study on effective wedding makeup using personal colors. Journal of the Korean Society of Beauty and Art, 13: 183-201, 2012.
Lee H, Kim S, Kim K, Hong K. Brain waves evoked by the changes of background pastel colors with a pattern of achromatic color. Fashion \& Textile Research Journal, 19: 653-660, 2017.

$\mathrm{Na}$ YY, Song SY. The influence on make-up behavior and cosmetics consumption tendency to interest in appearance of female middle school students: Gwangju area. Korea Science \& Art Forum, 18: 221-233, 2014.

Oh DS, Lee MS. The effects of make-up therapy on selfesteem and self-efficacy in melancholic patients. Journal of the Korean Society of Cosmetology, 24: 671679, 2018.

Park CY, Kim ES. The influence on fashion Mood in eyebrow shape and length of vogue Korea model: based on the vogue Korea from 2010 to 2015. Journal of the Korean Society of Design Culture, 23: 283-298, 2017.

Park HJ, Lee JM. A study on the expression technique of eye liner: on the basis of pacific makeup campaign from 1970s to 1990s. The Journal the Korean Society of Make-up Design, 4: 13-22, 2008.

Park JS, Park DE. Analysis of the average rate of change and curvature according to the type of angled and arched eyebrow makeup. Journal of Fashion Business, 23: 116126, 2019.

Ryu SJ. The influence of make-up on impressions. The Journal of the Korean Society of Make-up Design, 11: 25-32, 2015.

Schulz C, Kaufmann JM, Walther L, Schweinberger SR. Effects of anticaricaturing vs. caricaturing and their neural correlates elucidate a role of shape for face learning. Neuropsychologia, 50: 2426-2434, 2012.

Song MY, Park OL. A study on the perception of face type to makeup. Journal of the Korean Data Analysis Society, 6: 1543-1557, 2004.

Tagai $\mathrm{K}$, Shimakur $\mathrm{H}$, Isobe $\mathrm{H}$, Nittono $\mathrm{H}$. The light-makeup advantage in facial processing: evidence from eventrelated potentials. PLoS One, 12: e0172489, 2017.

Yun SH, Jung KH. Research about relationship between bridal make-up's color and image: with 2015's picturial magazine as the center. Journal of Basic Design \& Art, 17: 401-410, 2016. 


\section{국문초록}

\section{아이라이너 형태변화에 의한 남녀 뇌파반응과 감성평가 이미지 맵}

김민경

장안대학 뷰티케어과, 경기도 화성시, 한국

목적: 20 대 남녀 60 명을 대상으로 아이라이너의 형태를 변화시킨 자극물을 제시하여 뇌파와 감성평가 결과를 이용하여 이미 지 맵 구축과 동시에 뇌파와 감성반응의 상관관계를 파악하기 위함이다. 방법: 여섯 가지 아이라이너 형태에 의한 뇌파변동계수 (coefficient of variation for the brainwave, CVB)와 아이라이너 호감도와 평균선호도 지수(API) 파악하였다. 도출된 API지수를 형 용사 이미지 맵에 포지셔닝하였다. 뇌파와 감성평가에 대한 통계 분석은 SPSS를 사용하여 반복측정 분산분석(repeated measure analysis of variance)을 실시하였고, $95 \%$ 신뢰수준에서 Tukey's test를 통해 사후검증을 하였다. 결과: 남녀 모두 뇌파반응은 NL의 자극에서 $\alpha$ 파가 덜 감소하였으며, PU의 자극에서 $\beta$ 파, 파, SEF50과 SEF90가 가장 활성 되었다. 아이라이너의 형태변화에 의한 뇌파반응과 $\mathrm{API}$ 는 남녀 모두 비슷하였다. 남녀 모두 각각의 아이라이너 형태의 호감도와 뇌파변동계수와의 상관관계는 낮았으나 $\mathrm{API}$ 와 SEF50의 상관관계는 있었다. PU의 API위치는 남녀 모두 형용사 이미지 맵에서 양과 음의 이미지가 고르게 분포되었고 전반 적으로 강하고 동적 이미지로 평가하였다. 남녀 모두 아이라이너 호감도는 $\mathrm{BC}$ 가 가장 높았으며 $\mathrm{AA}$ 와 $\mathrm{NL}$ 형태에서도 호감도가 높 았다. 결론: 아이라이너의 형태변화에 의한 뇌파와 감성반응 결과들은 얼굴 이미지 표현을 위한 기본 방향성을 제시할 수 있을 것으 로 판단된다. 향후 다양한 눈모양에 아이라이너를 적용하여 생리적·감성적 반응의 상관관계를 도출하면 여성 이미지구축을 위한 과학적 데이터를 획득할 수 있을 것으로 사료된다.

핵심어: 아이라이너, 남녀, 뇌파반응, 감성반응, 이미지 맵

본 연구는 2019년도 장안대학교의 연구비 지원으로 수행된 것으로 이에 감사드립니다.

\section{참고문헌}

강근영. 인상의 형태학적 분석을 통한 얼굴 이미지 연구. 한국메이크업디자인학회지, 4: 279-288, 2008.

강수진, 유태순. 방송 제작시스템 변화에 따른 여성 앵커 메이크업 분석 및 시연. 한국디자인포럼, 53: 17-28, 2016.

고혜숙, 류지원. 여성 메이크업의 입술컬러와 지각자의 특성이 인상형성에 미치는 영향. 한국메이크업디자인학회지, 5 :

203-214, 2009.

고지형, 이진용. 퍼스널컬러를 이용한 효과적인 웨딩메이크업 연구. 한국인체미용예술학회지, 13: 183-201, 2012.

김민경. 다양한 아이라이너의 형태의 일러스트레이션이 얼굴 이미지에 미치는 감성반응 효과. 아시안뷰티화장품학술지,

12: 217-223, 2014.

김민경. 퍼스널 컬러진단 가이드 요인간 상관관계와 뇌파분석. 아시안뷰티화장품학술지, 14: 407-416, 2016.

김민경. 눈의 형태와 아이쉐도우 톤 변화에 따른 뇌 인지와 감성반응. 아시안뷰티화장품학술지, 15: 421-434, 2017.

김민경. 대조와 유사색 배색방법을 이용한 아이 쉐도우 색상자극의 뇌파와 감성반응. 아시안뷰티화장품학술지, 16: 509-

$521,2018$.

김민경, 류희욱. 눈 형태에 따른 스모키 메이크업의 감성 이미지. 감성과학, 14: 321-330, 2011.

김민경, 홍수경. Makeup Pattern Book. 지구, 파주, pp52-54, 2018.

김수영, 리순화. 한국, 중화권, 일본, 태국 여성의 포인트 메이크업에 따른 선호 및 이미지 연구. 아시안뷰티화장품학술지,

12: 709-717, 2014.

김은영, 김민경, 김선태, 류희욱. $\mathrm{EEG}$ 와 감성반응 분석에 의한 족욕과 라벤더 족욕의 이완과 진정 효과의 비교. 실내환경 
및 냄새학회지, 17: 122-131, 2018.

김정희. 메이크업을 위한 우리나라 성인 여성의 표준 얼굴 형태에 관한 연구. 복식, 57: 151-165, 2007.

김효숙, 강인애. 테마별 이미지 Make-up에 관한 연구. 패션 비지니스, 7: 72-83, 2003.

나윤영, 송선영. 여중생의 외모관심도가 화장행동 및 화장품 소비성향에 미치는 영향-광주지역을 중심으로. 한국과학예술

포럼, 18: 221-223, 2014.

류세자. 메이크업이 인상에 미치는 영향. 한국메이크업디자인학회지, 11: 25-32, 2015.

박정신, 박동은. 각진형과 아치형 눈썹메이크업의 평균변화율 및 곡률에 따른 형태구성의 중요요인 분석. 패션비즈니스,

23: 116-126, 2019.

박채영, 김은실. 보그 코리아(Vogue Korea) 잡지 모델의 눈썹 형태와 길이가 패션 분위기에 미치는 영향. 한국디자인문화

학회지, 23: 283-298, 2017.

박희진, 이정민. 시대별 아이라이너 표현기법에 관한 연구: 1970 1990년대 태평양 메이크업 캠페인을 중심으로. 한국메 이크업디자인학회지, 4: 13-22, 2008.

백수경, 이새벽, 안정려, 이정민. 컬러테라피가 적용된 메이크업에 관한 고찰. 미용예술경영연구, 7: 283-292, 2013.

송미영, 박옥련. 20 대 여성의 메이크업에 의한 얼굴의 형태 지각 연구. Journal of the Korean Data Analysis Society,

6: 1543-1557, 2004.

오대식, 이명선, 메이크업테라피가 우울증 환자의 자아존중감 및 자아효능감에 미치는 효과. 한국미용학회지, $24: 671-$

$679,2018$.

윤세희, 정강화. 신부메이크업 색채와 이미지의 상관관계에 관한 연구: 2015 년 잡지화보를 중심으로. 기초조형학연구,

17: 401-410, 2016.

이희란, 김소영, 김기성, 홍경희. 무채색 무늬가 포함된 배경색의 파스텔색상에 따른 뇌파반응. 한국의류산업학회지, $19:$ 653-660, 2017.

장윤정, 김민경, 류희욱. 방향유의 주요 성분인 옥사이드 물질(caryophyllene oxide, eucalyptol linalool oxide)의 흡입이 인간의 감성과 뇌파에 미치는 영향. 실내환경 및 냄새학회지, 16: 410-422, 2017.

정소명, 김민경. 류희욱. 자스민 농도변화가 뇌활성과 감성에 미치는 영향. 실내환경 및 냄새학회지, $14: 270-278$, 2015.

조미자. 컬러 트렌드를 활용한 이미지 메이크업 분석. 아시안뷰티화장품학술지, 16: 499-507, 2018.

최은미, 김숭현, 이윤진, 양정순, 김기영. 메이크업을 활용한 비대칭 눈의 보정효과. 한국인체미용예술학회지, $11: 1-12$, 2010.

한혜진. 일러스트레이션 얼굴 이미지의 메이크업 색채 효과. 한국색채학회 논문집, 29: 49-58, 2015. 


\section{中文摘要}

\section{根据眼线的形状变化男性和女性的脑电图反应和情绪评估图像映射}

金玟京

长安大学美容学科, 京畿道华城市, 韩国

目的: 本研究旨在通过向 30 名年龄在 20 岁左右的30名男性和 30 名女性提供修饰不同形式的眼线刺激来创建图 像地图并理解脑电图（EEG）与情绪反应之间的相关性。方法: 检测根据6种不同形式的眼线而变化的脑波变异 系数 (CVB) 和眼线的偏好度和平均偏好指数 (API)。分析了脑电波和好感度之间的相关性, 并尝试将得到 的API定位在形容词图像图上。对于统计分析, 使用SPSS进行重复测量方差分析, 然后在 $95 \%$ 置信水平下进行 Tukey检验。结果: 当无眼线（NL）刺激男性和女性参与者的EEG反应时， $\alpha$ 波减少; 当通过针刺眼线 (PU) 刺 激时, B波和ү波, SEF50和SEF90最显着地被激活。根据眼线形态变化, 男女显示出类似的EEG反应和API。尽 管男女每种形式的眼线的偏好度与API之间的相关性较低, 但API和SEF50之间存在高度相关性。在形容词图像 地图上, PU的API均匀分布在男性和女性参与者的正负图像范围内, 并且它们被完全评价为强烈和动态的。男 性和女性参与者都表现出对眼线的基本眼线（BC）形式的好感，其次是AA和NL。结论：脑电图和情绪反应的结 果, 取决于眼线形式的变化，提出了面部图像表达的基本方向。如果可以通过将眼线应用于各种眼形，可以获 得生理和情绪反应之间的相关性，该技术可以获得女性前瞻性图像构建的科学数据。

关键词: 眼线，男女，脑波，感性，图像映射 